\title{
Spatial vegetation distribution and zonal vegetation type on islands in southern part of the Lena Delta (Eastern Siberia)
}

\author{
Nikolay Lashchinskiy ${ }^{1,2 *}$ \\ ${ }^{1}$ Central Siberian Botanical Garden SB RAS, 630090 Novosibirsk, Russia \\ ${ }^{2}$ Trofimuk Institute for Petroleum Geology and Geophysics SB RAS, 630090 Novosibirsk, Russia
}

\begin{abstract}
In this research spatial distribution of the different vegetation types on Lena Delta islands described in connection with their relief, time of formation and geological substrates. It was shown that zonal vegetation can be find only on third river terrace on gentle slopes. Because of continuous permafrost predominant vegetation is presented by hydro serial communities united into successional cycles. Zonal vegetation types occupy not more than $1-2 \%$ of the whole area.
\end{abstract}

Zonal vegetation type or plakor vegetation reflects the local climate conditions and typically occures on flat well-drained surfaces underlined by loamy soil types. Determination of zonal vegetation type for any area is important for the understanding interconnections between climate and vegetation, estimation of the area ecological potential and for the prediction of vegetation dynamics in response on climate changes.

For the plains with minimal anthropogenic influence it could be expected that zonal vegetation will be predominant. But in some cases different ecological factors shifted ratio between zonal and serial vegetation so that zonal type occupies smaller area than serial vegetation. Sometimes it is really difficult to determine what kind of vegetation is zonal for the certain area.

Lena Delta is the biggest arctic river delta in a whole world [1]. It situated completely in tundra zone except of the most southern island Tit-Ary which is covered by the larch forest. All islands underlined by continuous permafrost. Thickness of the active layer varies depending on geomorphological position. We conducted vegetation survey on few model islands during field seasons 2017-2021. In addition, we've got high-resolution satellite images for the whole delta and very detailed images on few sites obtained with a help of Unmanned Aerial Vehicles (UAV). Combination of ground and remote sensing data allows us to describe spatial vegetation structure on different surfaces within southern part of delta.

In the southern part of delta four distinct surfaces different by their origin, age, elevation, relief and geological composition could be mentioned. [2]. The lowest and youngest one is floodplain elevated above lowest river level about 1-2 (max $6 \mathrm{~m})$. It

\footnotetext{
*Corresponding author: nick_lash@mail.ru
} 
composed of alluvial sands and has an active layer about $80-110 \mathrm{~cm}$. Age of this surface could be up to few hundred years.

There are two main factors which determined spatial vegetation structure and diversity on floodplain. First one is the distance from the main channel. This factor is roughly coincide with time of vegetation formation - the deeper inland situated vegetation the older it is. If in the vicinity of channel there are pioneer plant communities with low projective coverage, on a certain distance they changed to close willow thickets and farther to the communities with closed dense moss cover on the soil surface.

Second factor is floodplain relief. In general, there are three main relief features typical for the any floodplain: main flat surface, scroll bars and near-the-terrace depression. In our case there are no permafrost influence on floodplain relief because active layer is deep enough. Vegetation well indicates all these relief features by different communities. Geomorphological and vegetation maps made for the same floodplain site showed precise coincidence (Fig. 1). Of course there are no zonal vegetation on floodplain. It is flooded every year and underlined by pure sand.

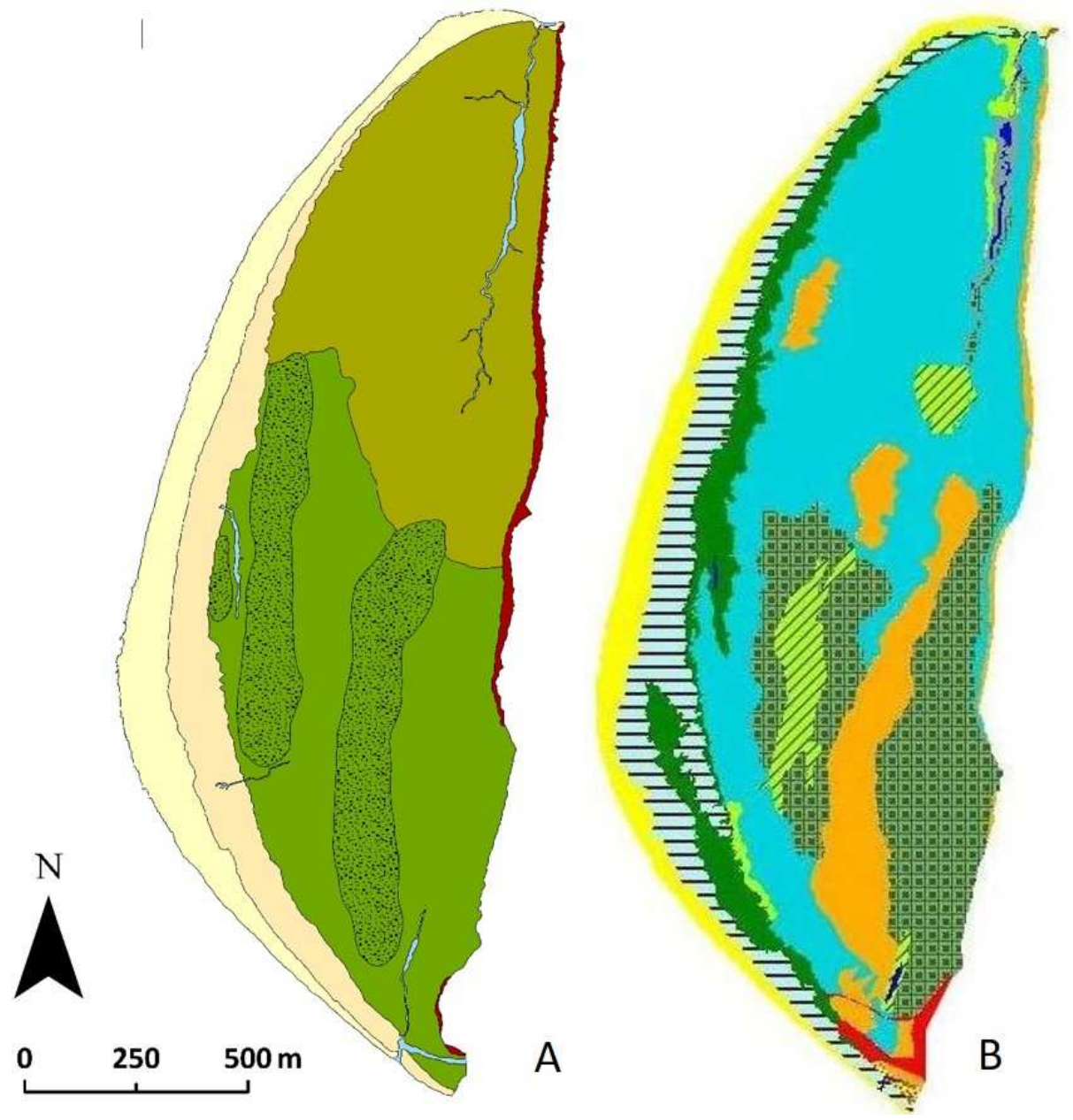

Fig. 1 Geomorphological (A) and vegetation maps of the floodplain segment.

The next surface is the first terrace elevated above the lowest river level about 4-6 (max $8 \mathrm{~m}$ ). Surface geological substrate is a mixture of fine send layers and of raw peat-like organic material broken by ice wedges into polygonal structures. Relief is mostly flat. 
Active layer is from 10 to $30 \mathrm{~cm}$ in dependence of microrelief features. Microrelief is well developed and represented by polygonal net of ice wedges. Numerous lakes are also typical for this surface. On a finer scale all surface divided into polygonal net with polygons roughly 20 to 20 (30) $\mathrm{m}$ with rims about $1-2 \mathrm{~m}$ width. Rims exceed polygon surface not more than $0,5 \mathrm{~m} \mathrm{[3].} \mathrm{This} \mathrm{is} \mathrm{the} \mathrm{most} \mathrm{common} \mathrm{surface} \mathrm{in} \mathrm{delta} \mathrm{and} \mathrm{it} \mathrm{occupies} \mathrm{about} 60$ to $70 \%$ of the whole area.

Vegetation of the first terrace strictly depends on microrelief. Rims occupied mostly by sedge-green moss tundra with Carex concolor and Hylocomium obtusifolium as main dominants. Vegetation in polygons depends on their profile (concave, flat or convex) and on water content inside. It could be wet tundra, different types of mires or water vegetation. Vegetation spatial structure looks like wet tundra matrix with small spots of other vegetation types imbedded in it (Fig. 2). No any zonal vegetation exists on the first terrace. The main reason for it - wet conditions and sandy substrate.

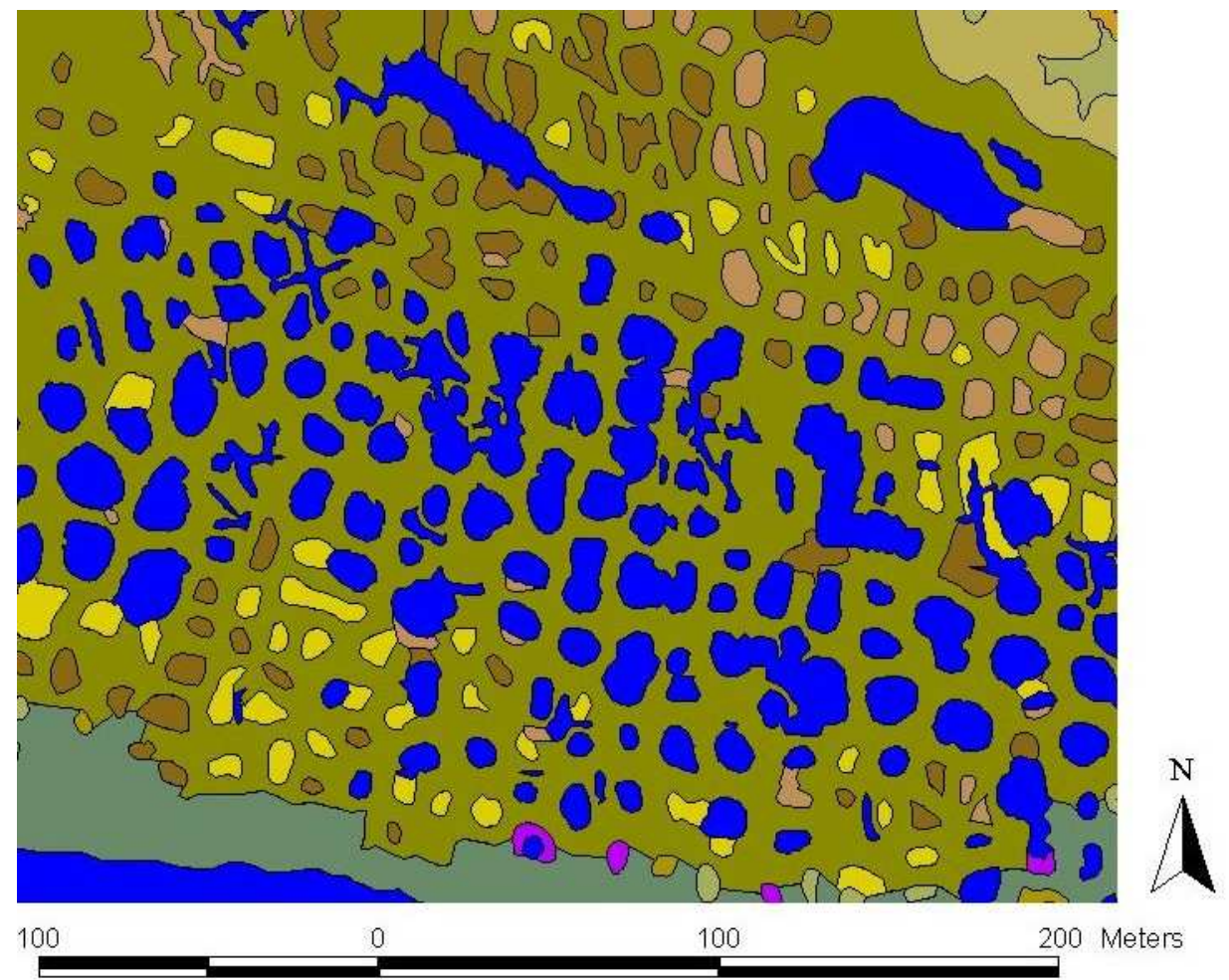

Fig. 2 Fragment of the first terrace vegetation map.

Next surface belongs to the third terrace. It is elevated about 30 to $50 \mathrm{~m}$ above the lowest water level and from the surface consists of so-called ice-complex - mixture of fine loam and syngenetic ice wedges of a big size. Relief is slightly wavy with numerous thermocarst lakes alive and dried out, pingos, creeks and valleys. Polygonal structures on the surface are nearly invisible in field but could be distinguished on UAV images. They are of comparable size with polygons on the first terrace. Active layer is about 30 to $40 \mathrm{~cm}$.

For the first glance this surface is ideal for zonal vegetation development. It is flat and underlined by loamy substrate. But the upper border of permafrost acts as water-proof layer. Because it is close to the soil surface $(30-40 \mathrm{~cm})$ soil is saturated with water on a flat surface. It could be drained only laterally on slopes. But if slope is step enough solifluction started on slopes exposed to the north, or soil becomes dry and over-drained on slopes 
exposed to the south. The only place suitable for zonal vegetation are gentle slopes with inclination 3 to 6 degrees around big lakes or creeks (Fig. 3). Here tussock tundra with Eriophorum vaginatum as main dominant could be observed. This vegetation type is widely distributed in Eastern Siberian Arctic and in Alaska. It is also recognized as zonal type for the mainland closed to Lena Delta [4]. It is obvious that zonal vegetation occupied not more than $10 \%$ of the third terrace. Predominant vegetation on flat surface is presented by moist tundra with willows (Salix pulchra, S. reptans) and green mosses (mostly Tomentypnum nitens).

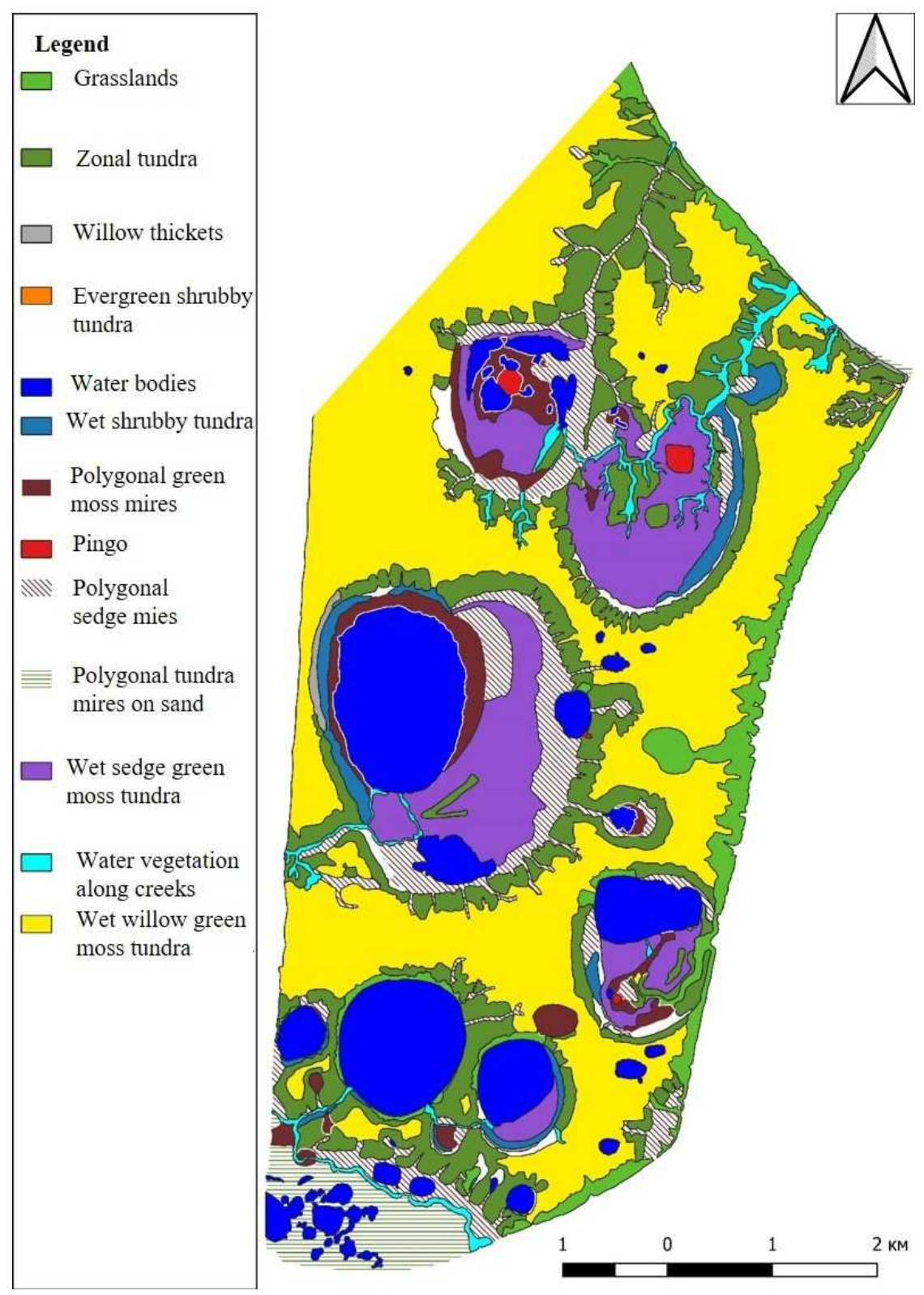

Fig. 3 Fragment of the third terrace vegetation map 
The last flat surface in southern part of delta is presented by bedrock outcrops. Their elevation could be from 50 to $100 \mathrm{~m}$ above sea level. Soil is gravelly and shallow. Thickness of an active layer is not possible to measure by metal stick because on the depth of $3-5 \mathrm{~cm}$ soil underlined by continuous bedrock. On flat or gently rounded hilltops soil is too shallow and stony to support zonal vegetation. Typical vegetation here is shrubby tundra with Dryas punctata and lichen tundra with Alectoria spp., Cetraria spp. and Cladonia spp. Zonal types could be found on foothills where slopes are gentle and soil enriched with fine earth.

\section{Conclusion}

In spite of the fact that more than $90 \%$ of delta area is perfectly flat zonal vegetation covers not more than $1 \%$ of the whole area. Most part of delta covered by hydroserial plant communities well-adapted to over-moist conditions. Because of permafrost zonal vegetation exists only on gentle slopes on loamy substrate sometimes mixed with gravel.

Spatial vegetation structure strictly controls by the relief development. Even slight differences in meso- or microrelief caused vegetation succession.

The study was carried out according to of the state assignment of the Central Siberian Botanical Garden of the Siberian Branch of the Russian Academy of Sciences state registration no. AAAA - A21 - 121011290026 - 9.

\section{References}

1. M.N. Grigoriev, Cryomorphogenesis of the Lena River mouth (Yakutsk, 1993)

2. G. Schwamborn, V. Rachold, M. N. Grigoriev, Quaternary International, 89 (2002)

3. A. A. Kartoziia, Remote Sens., 11(13) (2019)

4. N. A. Sekretareva, A. K. Sytin, Botanical journal, 91 (2006) 